\title{
ANALYSIS OF CHLOROPHYLL-A AND SUSPENDED SEDIMENT CONCENTRATION USING REMOTE SENSING IN MUTHUPET LAGOON, TAMIL NADU, INDIA
}

\author{
R. Nagalaskhmi ${ }^{1}$, P. M. Rameshwaran ${ }^{2}$, G. Kokila Priya ${ }^{2}$, G.Hemalatha ${ }^{2}$, \\ Justus Reymond ${ }^{1}$ and G. Premkumar ${ }^{1}$ \\ ${ }^{1}$ Civil Engineering Department, SRM Institute of Science and Technology, Kattankulathur, \\ Tamil Nadu, India \\ ${ }^{2}$ Civil Engineering Department, SRM University, Ramapuram, Tamil Nadu, India \\ E-mail: nagalakshmi.r@ktr.srmuniv.ac.in
}

\begin{abstract}
Chlorophyll-a and suspended sediment are significant water quality constraints to assess the hydrological environment in quantitatively. The high concentration of chlorophyll indicates nutrients contents have high in any types of water bodies and is not good for its ecosystem. Analysis of water quality parameters are very difficult in insitu measurement and have high expensive but advanced remote sensing technology can do with cost-effective manner and used for regular monitoring. The main objective of this study has developed a bio-optical algorithm in Muthupet lagoon, Vedaranniyam located in Nagapattinam district of Tamil Nadu, summer and monsoon season using IRS-P4 OCM sensor data and in-situ measurement for this the water samples have been collected in twelve locations when satellite overpass.

Keywords: Lagoon, OCM Sensor, Chlorophyll-a, Suspended Sediments, Monitoring, Bio-optical Algorithm.
\end{abstract}

(C) RASĀYAN. All rights reserved

\section{INTRODUCTION}

Lagoons are fully or partially separated water bodies from the ocean by sandbanks which are connected with the river in other side and always influenced by tidal action ${ }^{1,2}$. The management and monitoring of lagoons are very difficult due to the supply of both fresh and saline water inputs ${ }^{3}$. Muthupet lagoon enriches with mangroves and part of Vedaranyam coastal wetland connected with Cauvery river tributaries which carry sediments during monsoon season and effluents from chemical and salt industries around the lagoon. Water quality parameters are very important factors for all living organisms to survive 4,5 , it needs to monitor the water quality frequently and to conserve this ecosystem through proper management. Unplanned management of water quality parameters affects all components of an aquatic ecosystem it includes physical, chemical and biological properties of water ${ }^{6}$. Assessment of water quality can do using remote sensing technology with cost-effective manner. Remote sensing is an advanced technology for water quality assessment in different water resources such as a river, pond, groundwater, coastal and ocean water etc ${ }^{7,8,9}$. Remote sensing spectral characteristics are reflecting signals from earth features and the different water bodies having different chemical, physical and biological properties based on that reflecting pattern changing continuously which as not same for all the places and all sampling locations. The number of components like primary producers, suspended sediments and dead organic matters changes the spectral characteristics both qualitatively and quantitatively in the water bodies ${ }^{10}$. The spectral signature in water bodies depending on remote sensing sensor's bands and optical properties of water constituents based on the amount of absorption and reflection pattern will change ${ }^{11}$.

Chlorophyll-a and suspended sediments are essential to water excellence constraint responsible for primary productivity of all water bodies. Chlorophyll-a is used to calculate primary productivity, biomass, etc. Suspended sediment is the important pollutants which control the light transmission in the water,

Rasayan J. Chem., 12(2), 833-838(2019)

http://dx.doi.org/10.31788/RJC.2019.1225235

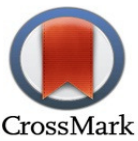


based on the light availability the primary productivity increase or decreases. The coastal dynamics also depending suspended sediment concentration ${ }^{12}$.

In this study mainly focus to create a bio-optical algorithm for the parameters of chl-a and SS by relating RS data and in-situ measurement taken from sampling location in summer and monsoon season in Muthupet lagoon. From this, in future devoid of the in-situ measurements can calculate their concentration with the help of spectral reflectance DN data.

Aim of the study is to create associations among chl-a and SS with remotely sensed data by the developed bio-optical algorithm in summer and monsoon season which is used to the quantification of these parameters in Muthupet lagoon.

\section{Study Area}

The study area situated in Nagapattinum district of Tamil Nadu, India. Located at the latitude of $10^{\circ}$ $15^{\prime} \mathrm{N}$ to $10^{\circ} 00^{\prime} \mathrm{N}$ and longitude of $79^{\circ} 20^{\prime} \mathrm{E}$ to $79^{\circ} 50^{\prime} \mathrm{E}$. Figure 1 shows the study area location map.

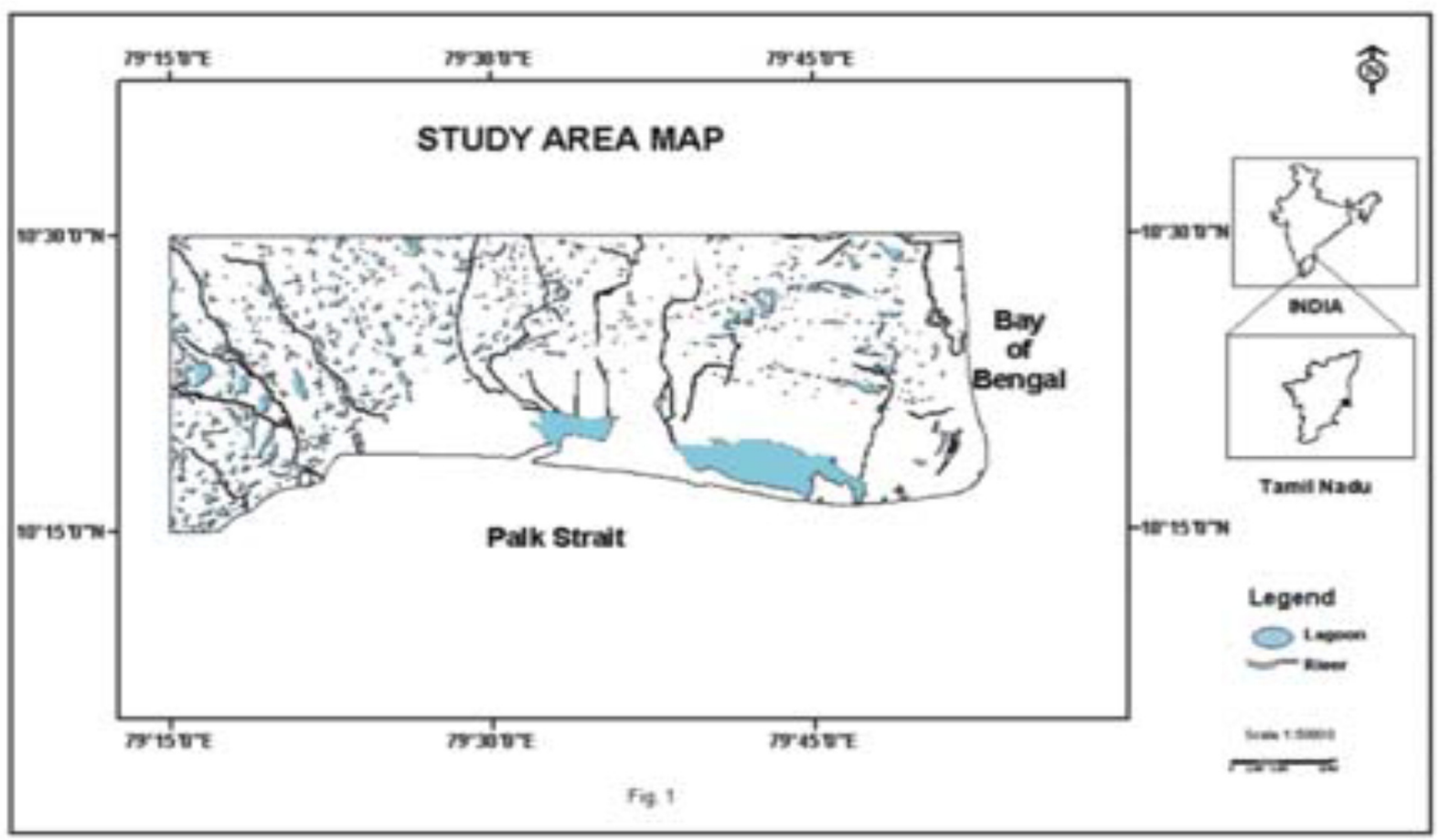

Fig.-1: Study Area Location Map

\section{EXPERIMENTAL}

Water samples have been collected for monsoon season 2017 and 2018 for the summer season at twelve sampling points in lagoons between $11.30 \mathrm{am}$ to $1.30 \mathrm{pm}$ when the satellite pass over the study area. Chlorophyll-a $\mathrm{mg} / \mathrm{m}^{3}$ and Suspended sediment $\mathrm{mg} / \mathrm{l}$ have been analyzed in the laboratory. IRS-P4 OCM Satellite data bought from National Remote Sensing Centre (NRSC), Hyderabad at the same date.

Using spectrophotometer the chlorophyll-a concentration has been predicted in the laboratory. The chlorophyll-a concentration has calculated by Parsons et al. ${ }^{13}$ calculation method. 500-1000 ml of water has been filtered through, 0.5 Millipore filter paper to get clean water and then to avoid acidity, a few drops of suspension of magnesium carbonate have been added on the filter. Chlorophyll-a pigment has been extracted from the filters in $90 \%$ acetone. The wavelengths involved are $750 \mathrm{~nm}, 664 \mathrm{~nm}, 647 \mathrm{~nm}$, and $630 \mathrm{~nm}$.

Suspended sediment (dry weight $\left(\mathrm{mg} \mathrm{L}^{-1}\right)$ ) has been determined gravimetrically as followed by Strickland and Parsons (1972) and as specified in JGOFS protocols UNESCO 1994 ${ }^{14}$. Samples have been filtered through pre-weighed polycarbonate filters $(0.4 \mu \mathrm{m})$. The filters have been washed with three 2.5 - 
$5 \mathrm{ml}$ aliquots of distilled water and immediately dried in an oven at $75^{\circ} \mathrm{C}$. The filters have then weighed again using an electron balance.

OCM data have been imported using ERDAS IMAGINE and geo-referencing of the image have been carried out and the geo-coding had been done by inputting the header file information and by using Survey of India (SOI) Toposheets. The next process is the atmospheric correction of the OCM sensor data. The scattered radiance magnitude comparing to desired backscattered limit due to reflection from the atmosphere, this magnitude radiance is named as water leaving radiance $L_{w}$. it needs the atmospheric correction in the OCM data. The aim of atmospheric correction is to retrieve $L_{w}$ as of the total radiance measured at the sensor, $L_{t}$. This atmospheric correction can be done by using ERDAS IMAGINE 9.1 software shown in Fig.-2. Regional bio-optical algorithms have been developed both summer and monsoon season in lagoon environment by multiple regression analysis in MATLAB software and analysis has been done connecting the spectral signature obtained from OCM information where processed SeaDAS software (Fig.-3) and in-situ measurements of chlorophyll and suspended sediments.

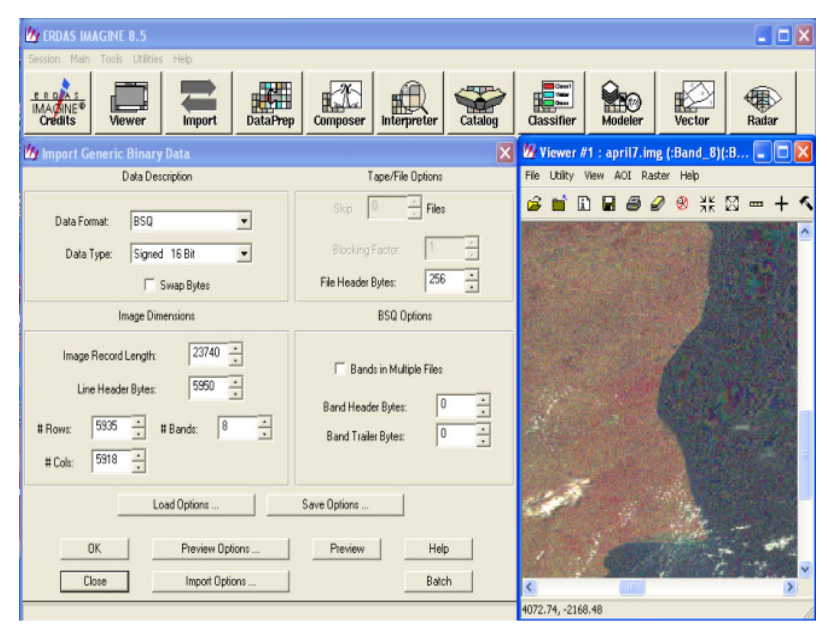

Fig.-2: Geo Rectification of OCM in ERDAS

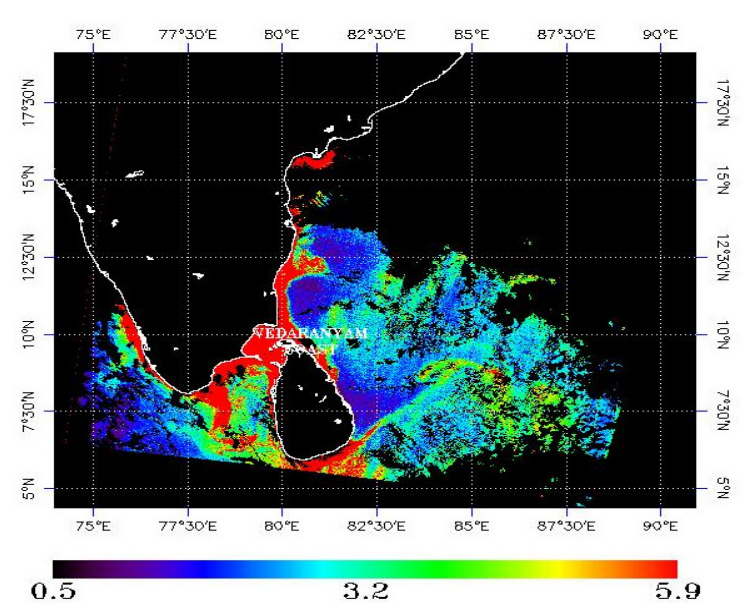

Fig.-3: OCM Sensor Value from sea DAS

\section{RESULTS AND DISCUSSION}

Bio-optical algorithm has been developed for Chlorophyll-a and suspended sediment suing DN values obtained from the atmospherically corrected OCM information and the in-situ trial values. During creating of regional bio-optical algorithm to consider the remote sensing data as independent data set and the in-situ measurements are dependent variables to construct their equations and OCM sensor has eight bands, out this only selected bands have used for developed algorithm such as band 2, 5, 6 (range 433$453,545-565,660-680 \mathrm{~nm}$ respectively) have been selected for chl-a and band 4, 5 (500-520, 545-565nm respectively) for SS. During monsoon (North West monsoon) season suspended sediment carried by rivers are huge and deposited in this study area, because of this chlorophyll-a concentration has been changed irrespectively, hence have developed regional algorithm for monsoon and summer season separately have shown below:

\section{For summer}

$$
\begin{aligned}
& \text { Chl-a }=2.52+0.00581 \mathrm{dn} 2+0.00535 \operatorname{dn} 5-0.0109 \operatorname{dn} 6 \\
& \mathrm{SS}=12.2-0.00488 \mathrm{dn} 4+0.00243 \mathrm{dn} 5
\end{aligned}
$$

\section{For monsoon}

$$
\begin{aligned}
& \text { Chl-a }=3.76+0.0241 \mathrm{dn} 2-0.00543 \mathrm{dn} 5-0.0206 \mathrm{dn} 6 \\
& \mathrm{SS}=7.24-0.00844 \mathrm{dn} 4+0.0181 \mathrm{dn} 5
\end{aligned}
$$

Here, Chl-a - chlorophyll-a concentration in $\mathrm{mg} / \mathrm{m}^{3}$, SS-suspended sediment concentration in $\mathrm{mg} / \mathrm{l}$ and digital number is the digital value

These algorithms can be used for estimating the chlorophyll-a and suspended sediment concentration in quantitatively with admiration to dn values of OCM information without any field sample values in the 
RASĀYAN J. Chem.

Vol. 12 | No. 2 |833 - 838| April - June | 2019

study area. Out of the twelve samples, eight sample values have been selected for algorithm development and four sample values have been used for validation of these algorithms shown in Table-1a and 1b.

Table-1(a): Samples Selected for Chlorophyll-a Algorithm Development in Monsoon Season, Lagoon Environment.

\begin{tabular}{c|c|l|c|c|c|c}
\hline Sampling points & Longitude & Latitude & band2 & band5 & band6 & Field Chl-a $\left(\mathrm{mg} / \mathrm{m}^{3}\right)$ \\
\hline & & & & & & \\
L1 & $79^{\circ} 32^{\prime} 27^{\prime \prime} \mathrm{E}$ & $10^{\circ} 20^{\prime} 01^{\prime \prime} \mathrm{N}$ & 26 & 88 & 88 & 2.06 \\
\hline L2 & $79^{\circ} 33^{\prime} 12^{\prime \prime} \mathrm{E}$ & $10^{\circ} 20^{\prime} 41^{\prime \prime} \mathrm{N}$ & 37 & 92 & 95 & 2.31 \\
\hline L3 & $79^{\circ} 3332^{\prime \prime} \mathrm{E}$ & $10^{\circ} 20^{\prime} 14^{\prime \prime} \mathrm{N}$ & 47 & 78 & 102 & 2.08 \\
\hline L4 & $79^{\circ} 34^{\prime} 13^{\prime \prime} \mathrm{E}$ & $10^{\circ} 20^{\prime} 09^{\prime \prime} \mathrm{N}$ & 52 & 86 & 68 & 2.44 \\
\hline L5 & $79^{\circ} 35^{\prime} 01^{\prime \prime} \mathrm{E}$ & $10^{\circ} 20^{\prime} 03^{\prime \prime} \mathrm{N}$ & 82 & 93 & 102 & 2.34 \\
\hline L6 & $79^{\circ} 32^{\prime} 55^{\prime \prime} \mathrm{E}$ & $10^{\circ} 19^{\prime} 50^{\prime \prime} \mathrm{N}$ & 33 & 142 & 99 & 2.36 \\
\hline L7 & $79^{\circ} 42^{\prime} 21^{\prime \prime} \mathrm{E}$ & $10^{\circ} 17^{\prime} 53^{\prime \prime} \mathrm{N}$ & 44 & 99 & 87 & 2.46 \\
\hline L8 & $79^{\circ} 42^{\prime} 57^{\prime \prime} \mathrm{E}$ & $10^{\circ} 17^{\prime} 21^{\prime \prime} \mathrm{N}$ & 57 & 79 & 54 & 2.73 \\
\hline
\end{tabular}

Table-1(b): Samples Selected for Validation

\begin{tabular}{c|c|c|c|c|c|c|c|c}
\hline $\begin{array}{c}\text { Sampling } \\
\text { points }\end{array}$ & Longitude & Latitude & DN2 & DN5 & DN6 & $\begin{array}{c}\text { Field Chl- } \\
\mathrm{a}\left(\mathrm{mg} / \mathrm{m}^{3}\right)\end{array}$ & $\begin{array}{c}\text { Computed } \\
\text { chl-a } \\
\left(\mathrm{mg} / \mathrm{m}^{3}\right)\end{array}$ & $\begin{array}{c}\text { Difference chl-a } \\
\left(\mathrm{mg} / \mathrm{m}^{3}\right)\end{array}$ \\
\hline L9 & $79^{\circ} 43^{\prime} 16^{\prime \prime} \mathrm{E}$ & $\begin{array}{l}10^{\circ} 18^{\prime} \\
25^{\prime \prime} \mathrm{N}\end{array}$ & 37 & 82 & 111 & 2.09 & 1.97 & 0.12 \\
\hline L10 & $79^{\circ} 43^{\prime} 51^{\prime \prime} \mathrm{E}$ & $\begin{array}{l}10^{\circ} 18^{\prime} \\
42^{\prime \prime} \mathrm{N}\end{array}$ & 33 & 47 & 74 & 2.03 & 2.15 & 0.12 \\
\hline $\mathrm{L} 11$ & $79^{\circ} 43^{\prime} 58^{\prime \prime} \mathrm{E}$ & $\begin{array}{l}10^{\circ} 17^{\prime} \\
52^{\prime \prime} \mathrm{N}\end{array}$ & 29 & 52 & 69 & 2.35 & 2.21 & 0.14 \\
\hline $\mathrm{L} 12$ & $79^{\circ} 44^{\prime} 47^{\prime \prime} \mathrm{E}$ & $\begin{array}{l}10^{\circ} 18^{\prime} \\
01^{\prime \prime} \mathrm{N}\end{array}$ & 41 & 59 & 74 & 2.38 & 2.26 & 0.12 \\
\hline
\end{tabular}

From the developing algorithms the values of chlorophyll-a and SS concentration have been derived and the variation among field values and the computed standards., the computed chlorophyll-a concentration in monsoon season varied from 0.06 to $0.76 \mathrm{mg} / \mathrm{m}^{3}$ (Fig.-4) comparing to field sample values and the computed chlorophyll-a concentration in summer season varied from 0.201 to $0.73 \mathrm{mg} / \mathrm{m}^{3}$ (Fig.-5) comparing to field sample values.

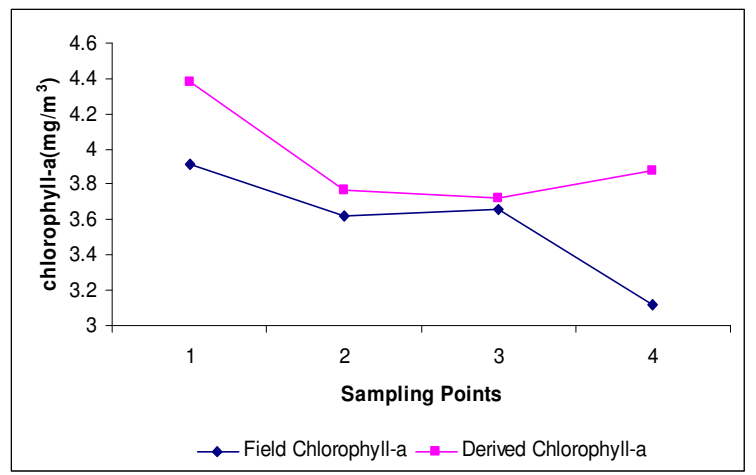

Fig.-4: Field Chl-a Standards and Computed Standards Differences - Monsoon.

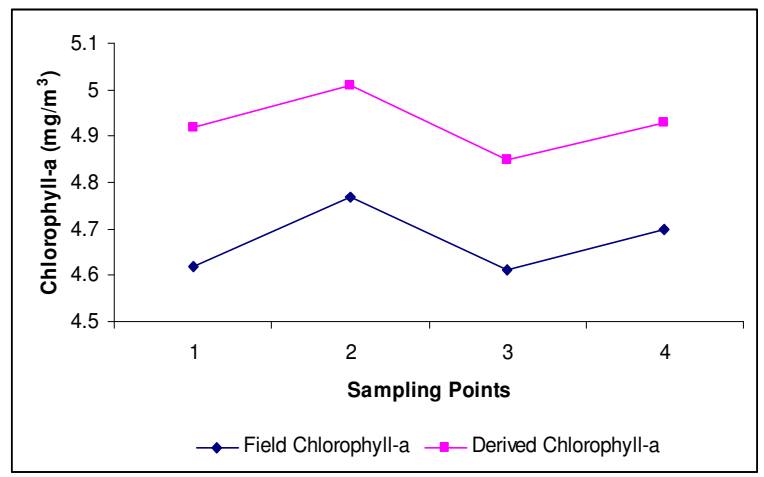

Fig.-5: Field Chl-a Standards and Computed Standards Differences-Summer.

In the monsoon season, the derived suspended sediment concentration diverse as of 0.13 to $0.22 \mathrm{mg} / \mathrm{l}$ (Fig.-6) comparing to in-situ sample standards and in the summer season, the computed suspended sediment concentration diverse as of 0.19 to $0.77 \mathrm{mg} / \mathrm{l}$ (Fig.-7) comparing to in-situ sample values. 
RASĀYAN J. Chem.

Vol. 12 | No. 2 |833 - 838| April - June | 2019

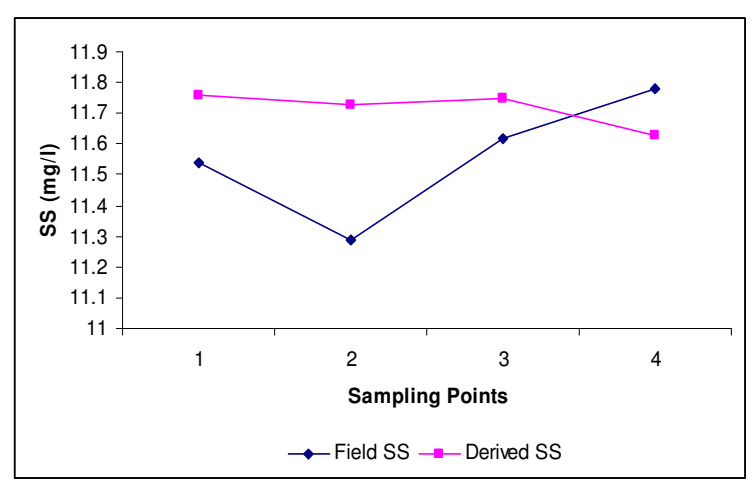

Fig.-6: Fields Suspended Sediment Values and Computed Standards Differences in Monsoon Season

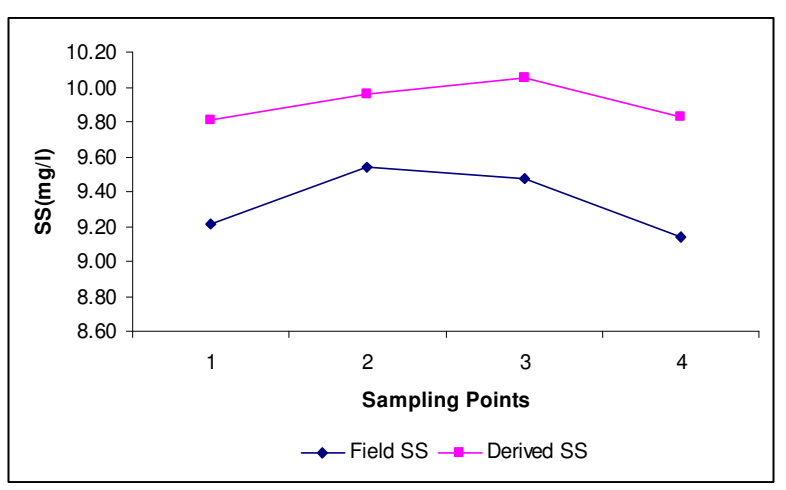

Fig.-7: Fields Suspended Sediment Standards and Computed Standards Differences in Summer Season

The result concludes the chlorophyll-a value does not a response to suspended sediment concentration in the lagoon. The chlorophyll concentration has high $\left(4.93 \mathrm{mg} / \mathrm{m}^{3}\right)$ in summer season and low $\left(2.06 \mathrm{mg} / \mathrm{m}^{3}\right)$ during monsoon (Fig.-8) and the suspended sediment attentiveness have high $11.76 \mathrm{mg} / \mathrm{l}$ during monsoon and low $6.78 \mathrm{mg} / \mathrm{l}$ in summer season(Fig.-9). During the monsoon river flow is heavy in the lagoon which is coming from Cauvery.

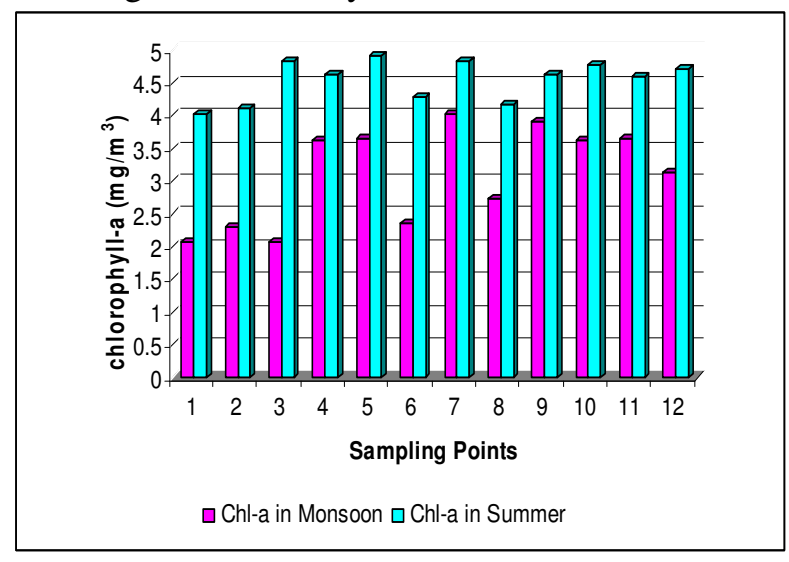

Fig.-8: Chlorophyll-a High in Summer and Low in Monsoon

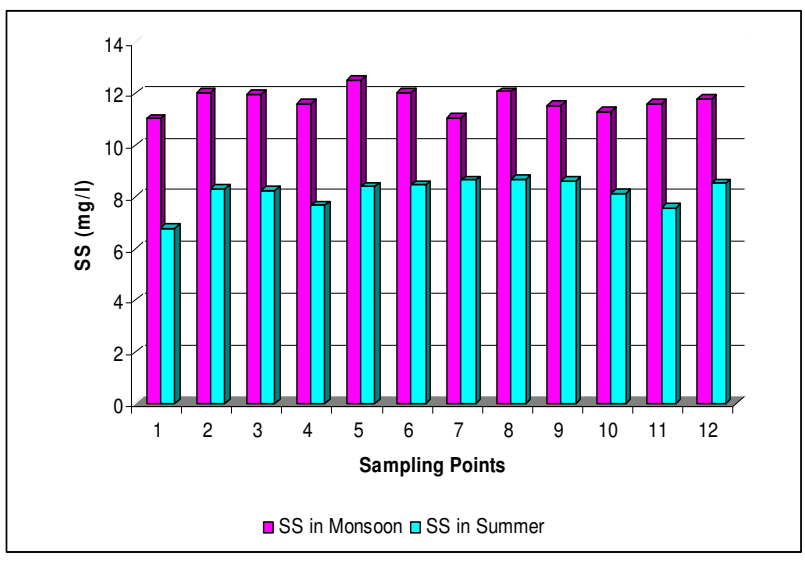

Fig.-9: Suspended Sediment High in Monsoon and Low in summer

\section{CONCLUSION}

The regional bio-optical algorithms have been developed using IRS P4 OCM sensor data in the study area. The concentrations of chlorophyll-a and suspended sediments are not evenly distributed because the wind action and the wave phenomenon affect continuously in this region. The developed algorithms gratify the Chlorophyll-a, suspended sediment attentiveness for both seasons with good accuracy. The advantage of this algorithm development is to generate the chlorophyll and suspended sediment concentration in the near future without in-situ measurements. On the other hand, in prospect, more samples at different periods of the year on behalf of the dissimilar spectral trait of the lagoon water are essential for taking a broad view of the algorithm. In this result point to that the being there of high turbidity significantly reduced light infiltration, hence the chlorophyll-a concentration is low during the monsoon that's limited photosynthesis activities. As a result, in the study area, primary production was controlled by light.

\section{REFERENCES}

1. S. B. Brown, J. D. Houghton and G. A. F. Hendry, Sheer CRC Press, Boca Raton FL pp 465-489 (1991)

2. C. M. Johnston and P. M. Gilliland, European Marine Site, p.9 (2000) 
3. R. N. Bamber, S. D. Batten and N. D. Bridgwater, Biodiversity and Conservation, 2, 127(1993).

4. R. Nagalakshmi , K. Prasanna and S. Prakash Chandar, Rasayan J. Chem., 9(4), 634 (2016)

5. R. Nagalakshmi , K. P. M. Rameshwaran and R. Santhosh, Rasayan J. Chem., 11(1), 181 (2018), DOI: $10.7324 /$ RJC.2018.1111774

6. R. Nagalakshmi and K. Prasanna, Rasayan J. Chem., 9(4), 798 (2016)

7. Han Z. and X. Yun,. Int. Journal of Remote Sensing, 27(19), 4329(2006).

8. A. G. Dekker et al., The Science of the Total Environment, 268,197(2001)

9. A. Gitelson et al., Remote Sensing of Environment, 109, 464(2007).

10. Asif M. Bhattia, Donald Rundquistb, John Schallesc, Mark Steeled, Masataka Takagie, Remote Sensing and Spatial Information Science, Volume XXXVIII, Part 8, Kyoto Japan (2010)

11. H. R. Gordon et al., Journal of Geophysical Research, 93, 10909_10924 (1988).

12. Ritchie, C. Jerry, Frank Schiebe, Remote Sensing in Hydrology and Water Management, Schultz A.G and Edwin T Engnan (2000).

13. T. R. Parsons and J. D. H. Strickland, Journal of Marine Research, 21, 155(1993).

14. P. Y. Julien and C. Vensel, UNESCO-ISI, 58p (2005)

[RJC-5235/2019] 